\title{
A novel approach to medical countermeasures against organophosphorus compound toxicity
}

\author{
TIAN WANG ${ }^{1 *}$, YUCUN WANG $^{2 *}$, LEIMING ZHANG $^{1}$, BING HAN $^{1}$, \\ HONGBO WANG $^{1}$, YOUXIN LI ${ }^{1,3}$ and FENGHUA FU ${ }^{1}$
}

\begin{abstract}
${ }^{1}$ Key Laboratory of Molecular Pharmacology and Drug Evaluation, Ministry of Education of China, School of Pharmacy, Yantai University, Yantai, Shandong 264005; ${ }^{2}$ Division of Gastroenterology, Yantaishan Hospital, Yantai, Shandong 264000; ${ }^{3}$ State Key Laboratory of Long-acting and Targeting Drug Delivery Technologies,

Luye Pharma Group Ltd., Yantai, Shandong 264003, P.R. China
\end{abstract}

Received July 25, 2013; Accepted September 13, 2013

DOI: 10.3892/br.2013.172

\begin{abstract}
The toxicity of organophosphorus compounds (OPs) results primarily from the irreversible inhibition of acetylcholinesterase (AChE). Huperzine A (HupA) is a reversible inhibitor of AChE and HupA sustained-release microspheres (HSMs) steadily release HupA, resulting in the continual inhibition of AChE activity for 14 days in mice. The present study aimed to investigate the preventive effects of HSMs on the toxicity of methyl parathion (MP). The mice were pretreated with HSMs followed by MP exposure. Subsequently, the median lethal dose $\left(\mathrm{LD}_{50}\right)$ and survival of the mice were determined. A histopathological examination of the brain, liver, lungs, heart, kidneys and intercostal muscles was also performed. The results revealed that the $\mathrm{LD}_{50}$ was $51.4 \mathrm{mg} / \mathrm{kg}$ in the control group and 70.0, 67.5, 63.4 and $53.5 \mathrm{mg} / \mathrm{kg}$ at $2 \mathrm{~h}, 5,10$ and 15 days after pretreatment with HSMs, respectively. Pretreatment with HSMs at 2 h, 5 days and 10 days prior to an acute challenge with $1.2 \times \mathrm{LD}_{50} \mathrm{MP}$ was sufficient to counteract the lethality and acute toxicity of MP. HSM pretreatment also attenuated the pulmonary edema induced by MP. The results demonstrated that pretreatment with HSMs may be an effective method to counteract MP poisoning. To the best of our knowledge, the present study was the first to demonstrate that pretreatment with an AChE reversible inhibitor sustained-release agent may be a novel approach to effective protection against OP toxicity.
\end{abstract}

Correspondence to: Professor Youxin Li or Professor Fenghua Fu, Key Laboratory of Molecular Pharmacology and Drug Evaluation, Ministry of Education of China, School of Pharmacy, Yantai University, 30 Qingquan Road, Yantai, Shandong 264005, P.R. China E-mail: youxinli@luye.cn

E-mail: fufenghua@sohu.com

${ }^{*}$ Contributed equally

Key words: huperzine A, methyl parathion, toxicity

\section{Introduction}

Organophosphorus compounds (OPs) are commonly used in agriculture as insecticides. Acute OP intoxication results primarily from the irreversible inhibition of acetylcholinesterase (AChE), which leads to acetylcholine accumulation and, consequently, overstimulation of cholinergic receptors in the peripheral and central nervous systems. Exposure to OPs is responsible for a significant number of deaths by poisoning annually (1).

The therapeutic strategies to decrease OP toxicity include atropine, to reduce the muscarinic syndrome, and pralidoxime, to reactivate OP-inhibited AChE (2). However, AChE inhibition by certain OPs may be refractory to reactivation by the clinically available oximes. Consequently, the fatality rate from OP poisoning remains high, despite treatment. Therefore, there is a need for a novel medical countermeasure for individuals who are prone to OP poisoning.

It was previously demonstrated that antibodies exhibited scavenger characteristics in the detoxication of OP poisoning (3). However, the limitations of immunotherapy are well recognized, as it takes a long time to provoke a potent antibody response against $\mathrm{OP}$ intoxication. It was demonstrated that pretreatment with physostigmine may protect against the incapacitating and lethal effects of OP poisoning (4). It was also demonstrated that OP toxicity and lethality are counteracted when galantamine is administered prior to acute exposure of guinea pigs to OPs (5). However, the ultimate usefulness of pyridostigmine and galantamine is questionable, as the time period during which they are effective against OPs intoxication is limited.

Huperzine A (HupA), an alkaloid isolated from the Chinese club moss Huperzia serrata, has been established as a slow, reversible inhibitor of $\mathrm{AChE}$ at the peripheral and central level (6). HupA sustained-release microspheres (HSMs), a new formulation of HupA, were prepared by an oil/water solvent evaporation technique loading poly(D, L-lactic-co-glycolic) acid (PLGA) microspheres with HupA. Following intramuscular injection of HSMs in mice, HupA was steadily released from the PLGA microspheres and the AChE activity was continually inhibited for 14 days (7). The present study aimed 
Table I. Groups for the evaluation of acute toxicity of methyl parathion.

\begin{tabular}{|c|c|c|c|c|c|}
\hline \multirow[b]{2}{*}{ Groups } & \multicolumn{5}{|c|}{ Subgroups according to dose of methyl parathion $(\mathrm{mg} / \mathrm{kg})$} \\
\hline & $1(\mathrm{n}=10)$ & $2(\mathrm{n}=10)$ & $3(n=10)$ & $4(n=10)$ & $5(\mathrm{n}=10)$ \\
\hline Control & 43.0 & 47.8 & 53.1 & 59.0 & 65.6 \\
\hline 2-h HSMs & 59.0 & 65.6 & 72.9 & 81.0 & 90.0 \\
\hline 5-day HSMs & 53.1 & 59.0 & 65.6 & 72.9 & 81.0 \\
\hline 10-day HSMs & 53.1 & 59.0 & 65.6 & 72.9 & 81.0 \\
\hline 15-day HSMs & 47.8 & 53.1 & 59.0 & 65.6 & 72.9 \\
\hline
\end{tabular}

HSMs, huperzine A sustained-release microspheres.

to investigate whether HSM pretreatment is effective in counteracting the toxicity of OPs.

\section{Materials and methods}

Drug and chemicals. Methyl parathion (MP) $(80 \%, w / w)$ was obtained from Shandong Dacheng Pesticide Co., Ltd. (Zibo, China). The HSMs were provided by Shandong Luye Pharmaceutical Co., Ltd. (Yantai, China).

Animals. A total of 370 Swiss mice, weighing 20-22 g, were provided by the Experimental Animal Center of the Shandong Engineering Research Center for Natural Drugs (Yantai, China). The animals were housed in a climate-controlled room, maintained on a $12 \mathrm{~h} / 12 \mathrm{~h}$ light/dark cycle and had ad libitum access to food and water. The experiments were performed according to the National Institute of Health Guidelines for the Care and Use of Laboratory Animals (publication no. 86-23, revised in 1986) and were approved by the local Ethics Committee. All efforts were made to minimize the number of animals used and their suffering.

Acute toxicity of MP in HSM-pretreated mice. The mice were randomly divided into 5 groups $(\mathrm{n}=50$ mice/group) as follows: control, 2-h HSMs, 5-day HSMs, 10-day HSMs and 15-day HSMs groups. According to the doses of MP, the mice were further subdivided into 5 subgroups ( $n=10$ mice/subgroup) (Table I). After fasting for $12 \mathrm{~h}$, the mice in the control group were treated intramuscularly with $2.5 \%$ (w/v) sodium carboxymethyl cellulose. The mice were then challenged by a single intragastric exposure to MP at doses of 43.0, 47.8, 53.1, 59.0 and $65.6 \mathrm{mg} / \mathrm{kg}$. The mice in the 2-h HSMs subgroups were treated intramuscularly with HSMs at a dose of $1.5 \mathrm{mg} / \mathrm{kg}$. Two hours later, they were intragastrically challenged with MP at doses of 59.0, 65.6, 72.9, 81.0 and $90.0 \mathrm{mg} / \mathrm{kg}$. The mice in the 5-day HSMs subgroups were treated intramuscularly with HSMs at a dose of $1.5 \mathrm{mg} / \mathrm{kg}$. Five days later, they were intragastrically challenged with MP at doses of 53.1, 59.0, 65.6, 72.9 and $81.0 \mathrm{mg} / \mathrm{kg}$. The mice in the 10-day HSMs subgroups were treated intramuscularly with HSMs at a dose of $1.5 \mathrm{mg} / \mathrm{kg}$. Ten days later, they were intragastrically challenged with MP at doses of $53.1,59.0,65.6,72.9$ and $81.0 \mathrm{mg} / \mathrm{kg}$. The mice in the 15-day HSMs subgroups were treated intramuscularly with HSMs at a dose of $1.5 \mathrm{mg} / \mathrm{kg}$. Fifteen days later, they
Table II. Effect of HSMs on the $\mathrm{LD}_{50}$ of methyl parathion.

\begin{tabular}{lccc}
\hline Groups & $\begin{array}{c}\text { HSMs dose } \\
(\mathrm{mg} / \mathrm{kg})\end{array}$ & $\begin{array}{c}\mathrm{LD}_{50} \\
(\mathrm{mg} / \mathrm{kg})\end{array}$ & $95 \% \mathrm{CI}$ \\
\hline Control & - & 51.4 & $46.8-56.4$ \\
2-h HSMs & 1.5 & 70.0 & $64.6-75.8$ \\
5-day HSMs & 1.5 & 67.5 & $62.3-73.0$ \\
10-day HSMs & 1.5 & 63.4 & $57.8-69.7$ \\
15-day HSMs & 1.5 & 53.5 & $49.2-58.2$ \\
\hline
\end{tabular}

HSMs, huperzine A sustained-release microspheres; $\mathrm{LD}_{50}$, median lethal dose; CI, confidence interval.

were intragastrically challenged with MP at doses of 47.8, $53.1,59.0,65.6$ and $72.9 \mathrm{mg} / \mathrm{kg}$. The general behavior and signs of toxicity in mice were observed continuously for $1 \mathrm{~h}$ following MP administration and then intermittently for $4 \mathrm{~h}$ over a period of $24 \mathrm{~h}$. The mice were further observed once a day up to 14 days for behavioral changes and signs of toxicity and/or death. The value of the median lethal dose $\left(\mathrm{LD}_{50}\right)$ was determined as previously described (8).

Evaluation of HSM pretreatment on MP poisoning. The mice were randomly divided into 3 groups ( $\mathrm{n}=40 \mathrm{mice} / \mathrm{group}$ ): Control, MP and HSMs groups. The mice in the control group were further subdivided into 4 subgroups: 2-h, 5-day, 10-day and 15-day control subgroups. The mice in the MP group were further subdivided into 4 subgroups: 2-h, 5-day, 10-day and 15-day MP subgroups. The mice in the HSMs group were further divided into 4 subgroups: 2-h, 5-day, 10-day and 15-day HSMs subgroups. The mice in the control subgroups were treated intramuscularly with $2.5 \%(\mathrm{w} / \mathrm{v})$ sodium carboxymethyl cellulose. Two hours, 5, 10 and 15 days later, they were intragastrically administered distilled water. The mice in the MP subgroups were treated intramuscularly with $2.5 \%$ (w/v) sodium carboxymethyl cellulose. Two hours, 5, 10 and 15 days later, they were intragastrically administered MP at a dose of $60.0 \mathrm{mg} / \mathrm{kg}$ $\left(1.2 \times \mathrm{LD}_{50}\right)$. The mice in the HSMs subgroups were treated intramuscularly with HSMs at a dose of $1.5 \mathrm{mg} / \mathrm{kg}$. Two hours, 5, 10 and 15 days later, they were intragastrically administered MP at a dose of $60.0 \mathrm{mg} / \mathrm{kg}$. The general behavior and signs of toxicity in mice were observed continuously for $1 \mathrm{~h}$ after the MP 
Table III. Effects of HSMs on methyl parathion poisoning in mice.

\begin{tabular}{|c|c|c|c|c|c|c|c|}
\hline \multirow[b]{2}{*}{ Groups } & \multicolumn{5}{|c|}{ No. of euthanized animals } & \multirow[b]{2}{*}{ Total deaths } & \multirow[b]{2}{*}{ Survival, $\%$} \\
\hline & $5-15 \min$ & $15-25 \mathrm{~min}$ & $35-45 \min$ & $45-60 \mathrm{~min}$ & $12-24 \mathrm{~h}$ & & \\
\hline \multicolumn{8}{|l|}{ A } \\
\hline Control & 0 & 0 & 0 & 0 & 0 & 0 & 100 \\
\hline MP & 1 & 3 & 0 & 0 & 2 & 6 & 40 \\
\hline 2-h HSMs & 0 & 0 & 0 & 0 & 0 & 0 & $100^{\mathrm{b}}$ \\
\hline \multicolumn{8}{|l|}{ B } \\
\hline Control & 0 & 0 & 0 & 0 & 0 & 0 & 100 \\
\hline MP & 1 & 3 & 0 & 0 & 2 & 6 & 40 \\
\hline 5-day HSMs & 0 & 0 & 0 & 0 & 1 & 1 & $90^{\mathrm{a}}$ \\
\hline \multicolumn{8}{|l|}{$\mathrm{C}$} \\
\hline Control & 0 & 0 & 0 & 0 & 0 & 0 & 100 \\
\hline MP & 2 & 3 & 0 & 1 & 2 & 8 & 20 \\
\hline 10-day HSMs & 0 & 1 & 0 & 0 & 1 & 2 & $80^{\mathrm{b}}$ \\
\hline \multicolumn{8}{|l|}{$\mathrm{D}$} \\
\hline Control & 0 & 0 & 0 & 0 & 0 & 0 & 100 \\
\hline MP & 2 & 2 & 1 & 0 & 2 & 7 & 30 \\
\hline 15-day HSMs & 0 & 3 & 0 & 2 & 2 & 7 & 30 \\
\hline
\end{tabular}

A: Mice were treated intramuscularly (IM) with huperzine A sustained-release microspheres (HSMs) $2 \mathrm{~h}$ prior to the exposure to methyl parathion (MP). B: Mice were treated IM with HSMs 5 days prior to the exposure to MP. Mice were treated IM with HSMs 10 days prior to the exposure to MP. D: Mice were treated IM with HSMs 15 days prior to the exposure to MP. ${ }^{a} \mathrm{P}<0.05$, ${ }^{\text {}} \mathrm{P}<0.01$ compared to the MP group.

administration and then intermittently for $4 \mathrm{~h}$ over a period of $24 \mathrm{~h}$. The mice were further observed once a day up to 14 days for behavioral changes and signs of toxicity and/or death. Acute reactions to treatment were scored according to a modified Racine scale (9). Whenever animals developed life-threatening signs of intoxication, such as gasping and unremitting motor convulsions, they were euthanized according to the Institutional Animal Care and Use Committee-approved protocol.

Histopathological analysis. Following euthanasia, the brain, heart, liver, lungs, kidneys and intercostal muscles of the mice were harvested. Subsequently, paraformaldehyde (4\%)-fixed, paraffin-embedded samples were cut into 4- $\mu \mathrm{m}$ sections, deparaffinized in xylene and rehydrated through a series of decreasing concentrations of ethanol. The sections were stained with hematoxylin and eosin and pathological observation of the tissues was performed under a light microscope.

Statistical analysis. In order to calculate the $\mathrm{LD}_{50}$, a linear regression analysis corrected for the number of animals at each dose level was used. The proportion of dead mice and the logarithmic transformed dose levels were used as the dependent and independent variables, respectively. The survival rates were compared using the Kaplan-Meier log-rank test. $\mathrm{P}<0.05$ was considered to indicate a statistically significant difference.

\section{Results}

Effect of HSMs on the $L D_{50}$ of MP. The $\mathrm{LD}_{50}$ of MP in the mice of the control group was $51.4 \mathrm{mg} / \mathrm{kg}$. Compared to the control group, animals in the 2-h, 5-day and 10-day HSMs groups were more resistant to the toxic effects of $\mathrm{MP}\left(\mathrm{LD}_{50}=70.0,67.5\right.$ and $63.4 \mathrm{mg} / \mathrm{kg}$, respectively). However, the $\mathrm{LD}_{50}$ value of $\mathrm{MP}$ in the 15-day HSMs group $(53.5 \mathrm{mg} / \mathrm{kg}$ ) was the same as that of the control group (Table II).

Effect of HSMs on the acute toxicity of $1.2 \times L D_{50} M P$. Within 25 min after a single intragastric administration of MP at a dose of $60 \mathrm{mg} / \mathrm{kg}, \sim 40 \%$ of the mice developed a cholinergic crisis characterized by chewing, miosis, hypersecretion, diarrhea, bruxism, muscle fasciculations and tremors. According to the Institutional Animal Care and Use Committee-approved protocol, the animals were euthanized as soon as signs of intoxication became life threatening. Approximately 20-40\% of the mice survived for $24 \mathrm{~h}$ after exposure to $1.2 \mathrm{x} \mathrm{LD}_{50} \mathrm{MP}$.

Effects of HSMs on the manifestation of MP poisoning in mice. Following MP exposure, all the mice in the 2-h HSMs group survived, with no apparent toxic signs. The mice in the 5-day and 10-day HSMs groups developed mild adverse symptoms, such as increased chewing, hypersalivation and tremors. The toxic signs in the mice of the 2-h, 5-day and 10-day HSMs groups were significantly attenuated. Furthermore, the 24-h survival of the animals in the 2-h, 5-day and 10-day HSMs groups was 100,90 and $80 \%$, respectively $(\mathrm{P}<0.05$ or $\mathrm{P}<0.01)$. The animals in the 15-day HSMs group developed severe signs of intoxication, with a $24-\mathrm{h}$ survival of $30 \%$ (Table III).

Effects of HSMs on histopathological changes induced by MP poisoning. The examination under a light microscope revealed 


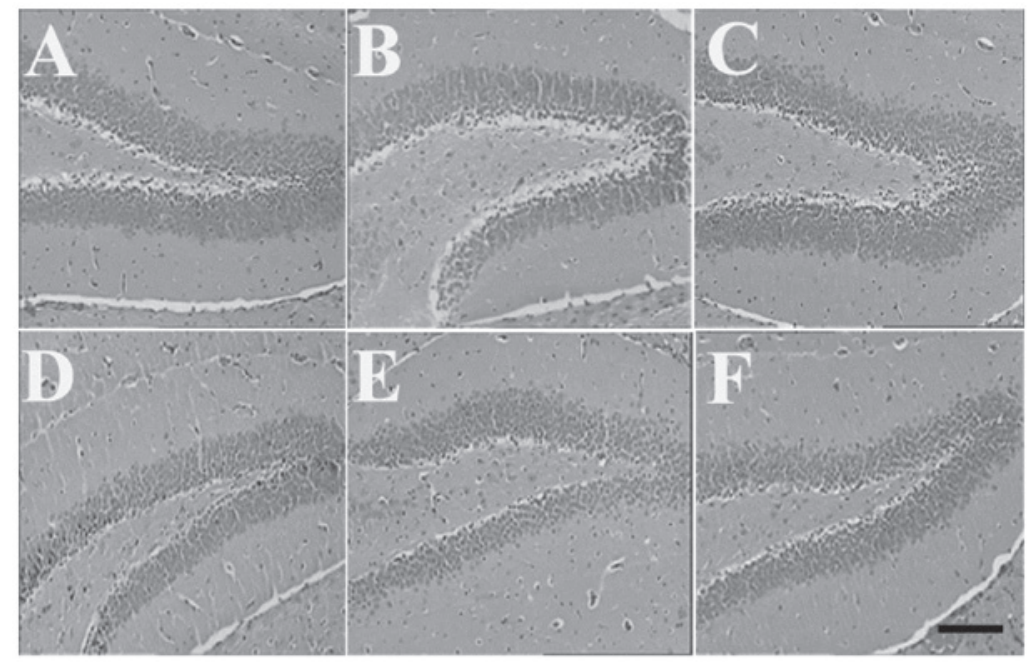

Figure 1. Effects of huperzine A sustained-release microspheres (HSMs) on the histopathological changes of the brain induced by methyl parathion (MP) poisoning. The mice were treated intramuscularly with $2.5 \%(\mathrm{w} / \mathrm{v})$ sodium carboxymethyl cellulose or HSMs followed by a single intragastric administration of $1.2 \times$ LD $_{50}$ MP. (A) Control group. (B) MP group. (C) 2-h HSMs group. (D) 5-day HSMs group. (E) 10-day HSMs group. (F) 15-day HSMs group. Bar=200 $\mu \mathrm{m}$.

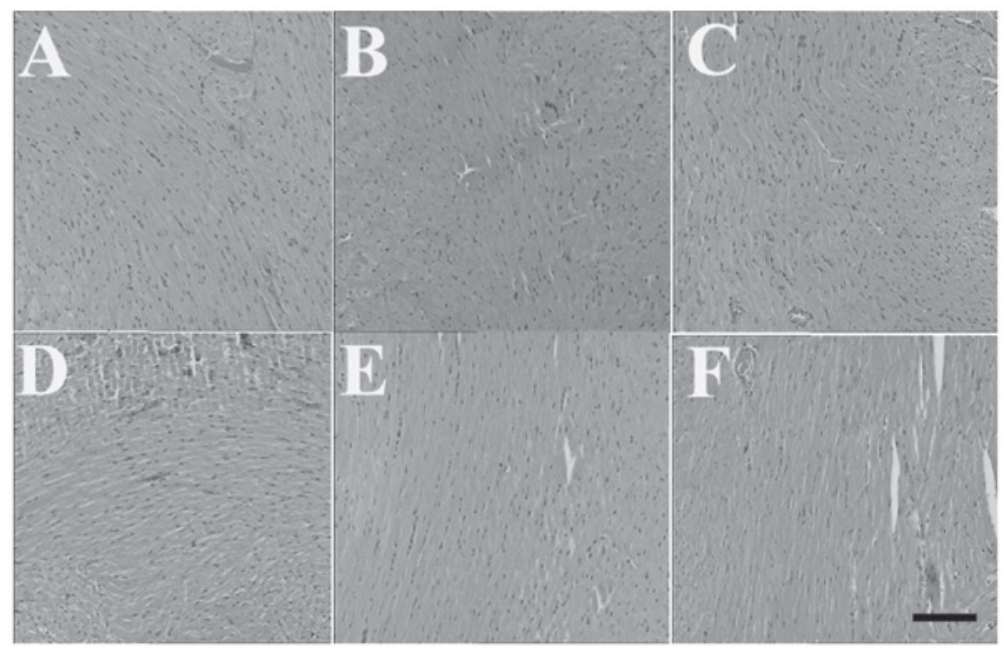

Figure 2. Effects of huperzine A sustained-release microspheres (HSMs) on the histopathological changes of the heart induced by methyl parathion (MP) poisoning. The mice were treated intramuscularly with $2.5 \%$ (w/v) sodium carboxymethyl cellulose or HSMs followed by a single intragastric administration of $1.2 \times \mathrm{LD}_{50}$ MP. (A) Control group. (B) MP group. (C) 2-h HSMs group. (D) 5-day HSMs group. (E) 10-day HSMs group. (F) 15-day HSMs group. Bar=200 $\mu \mathrm{m}$.

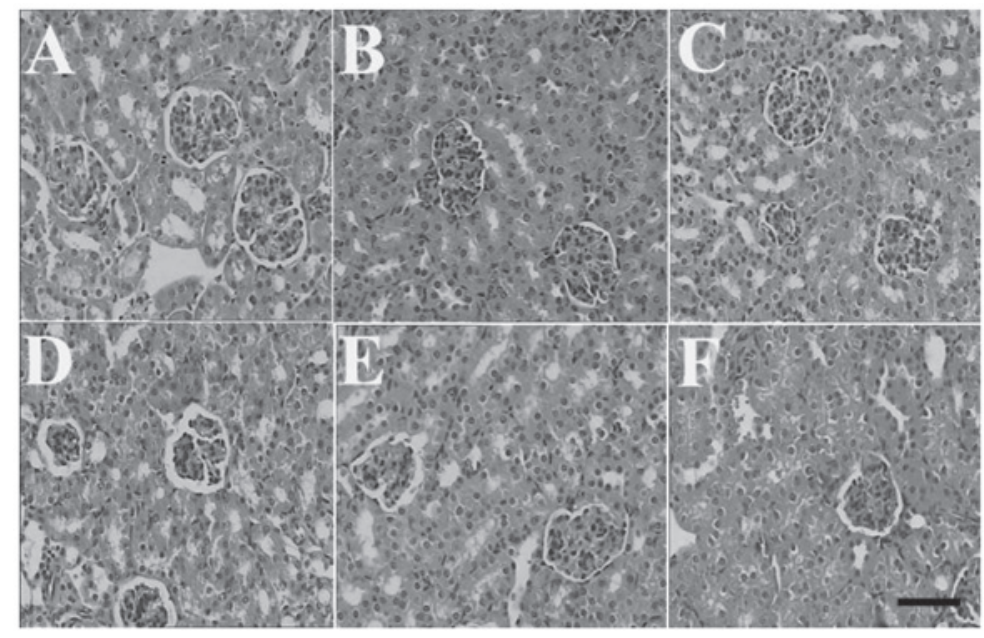

Figure 3. Effects of huperzine A sustained-release microspheres (HSMs) on the histopathological changes of the kidneys induced by methyl parathion (MP) poisoning. The mice were treated intramuscularly with $2.5 \%(\mathrm{w} / \mathrm{v})$ sodium carboxymethyl cellulose or HSMs followed by a single intragastric administration of $1.2 \times$ LD $_{50}$ MP. (A) Control group. (B) MP group. (C) 2-h HSMs group. (D) 5-day HSMs group. (E) 10-day HSMs group. (F) 15 -day HSMs group. Bar=200 $\mu$ m. 


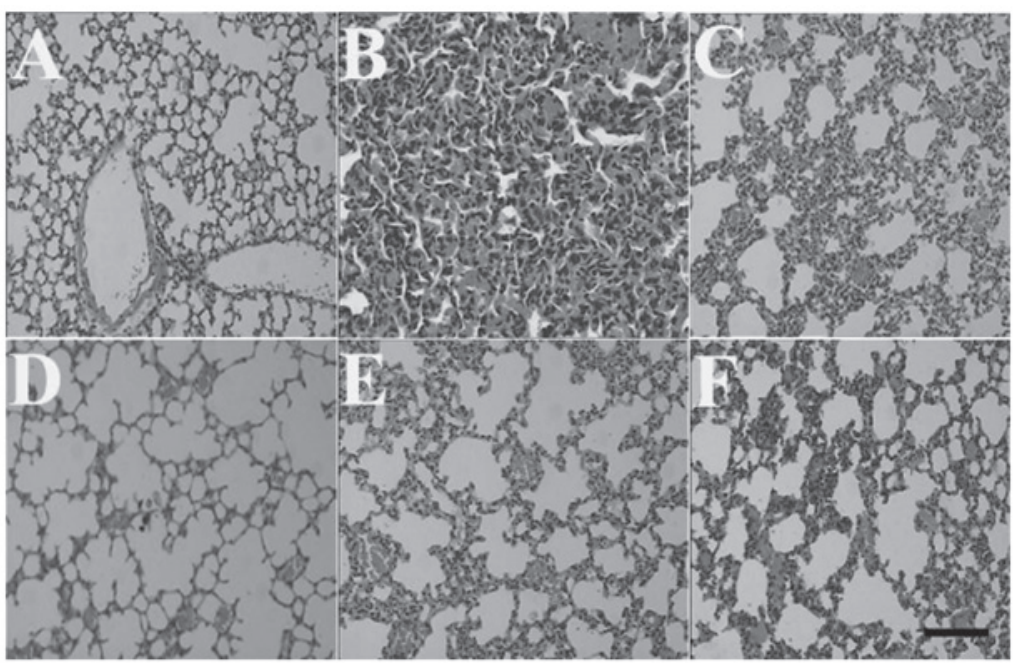

Figure 4. Effects of huperzine A sustained-release microspheres (HSMs) on the histopathological changes of the lungs induced by methyl parathion (MP) poisoning. The mice were treated intramuscularly with $2.5 \%(\mathrm{w} / \mathrm{v})$ sodium carboxymethyl cellulose or HSMs followed by a single intragastric administration of $1.2 \times$ LD $_{50}$ MP. (A) Control group. (B) MP group. (C) 2-h HSMs group. (D) 5-day HSMs group. (E) 10-day HSMs group. (F) 15-day HSMs group. Bar=200 $\mu \mathrm{m}$.

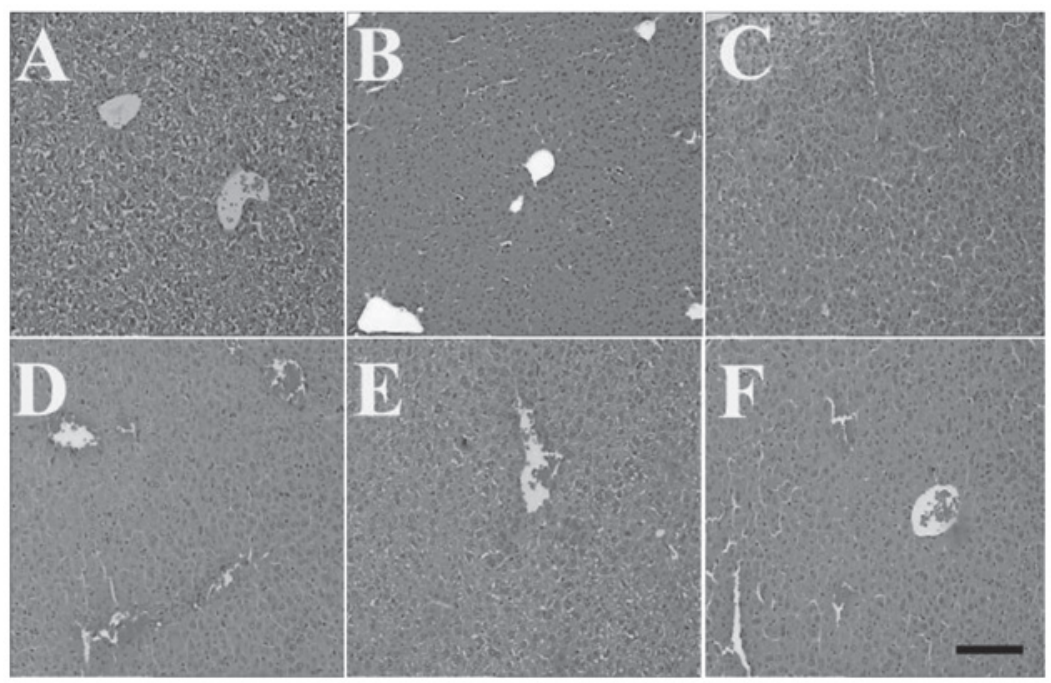

Figure 5. Effects of huperzine A sustained-release microspheres (HSMs) on the histopathological changes of the liver induced by methyl parathion (MP) poisoning. The mice were treated intramuscularly with $2.5 \%$ (w/v) sodium carboxymethyl cellulose or HSMs followed by a single intragastric administration of $1.2 \times$ LD $_{50}$ MP. (A) Control group. (B) MP group. (C) 2-h HSMs group. (D) 5-day HSMs group. (E) 10-day HSMs group. (F) 15-day HSMs group. Bar=200 $\mu$ m.

a normal structure of the brain, heart and kidneys of the control animals. The brain, heart and kidneys of the mice in the MP and HSMs groups also revealed no histological changes (Figs. 1, 2 and 3, respectively). However, the livers of the mice in the MP and HSMs groups displayed central vein congestion as a result of the exposure to MP. The lungs of the animals in the MP group exhibited a notable pulmonary edema that was characterized by edema and congestion of the alveolar septae. However, the histopathological changes of the lungs in the 2-h, 5-day and 10-day HSMs groups were significantly less prominent, whereas the histopathological changes of the lungs in the 15-day HSMs group were identical with those of the MP group (Fig. 4). Furthermore, pretreatment with HSMs did not attenuate the MP-induced central vein congestion in the liver (Fig. 5).

\section{Discussion}

In the present study, HSMs pretreatment was shown to increase the value of the $\mathrm{LD}_{50}$ and the survival of animals poisoned by MP. The results demonstrated that pretreatment with HSMs, even 10-days prior to MP exposure, may effectively counteract the toxicity of OPs.

MP poisoning leads to cholinergic overstimulation, with signs of toxicity such as sweating, dizziness, vomiting, diarrhea, convulsions, cardiac arrest, respiratory arrest and, in extreme cases, death. In toxicology, the median $\mathrm{LD}_{50}$ is frequently used as a general indicator of the acute toxicity of a substance. The $\mathrm{LD}_{50}$ of MP in the control group was $51.4 \mathrm{mg} / \mathrm{kg}$. However, the $\mathrm{LD}_{50}$ values of the 2-h, 5-day and 10-day HSMs groups were $70.0,67.5$ and $63.4 \mathrm{mg} / \mathrm{kg}$, respectively, which were equivalent 
to $1.36,1.31$ and 1.23 times the dose in mice without administering HSMs. There was no significant difference in the $\mathrm{LD}_{50}$ between the control group and the 15-day HSMs group. The acute toxicity of MP $\left(1.2 \times \mathrm{LD}_{50}\right)$ was also effectively counteracted by pretreatment with HSMs. Approximately $60-80 \%$ of the mice in the MP groups developed life threatening symptoms and were euthanized. By contrast, the mice pretreated with HSMs 2 h, 5 days and 10 days prior to MP exposure survived (100, 90 and $80 \%$, respectively), with mild signs of toxicity. These results demonstrated the high, long-term effectiveness of HSMs against the toxicity of $1.2 \times \mathrm{LD}_{50} \mathrm{MP}$.

The organ injury caused by OP exposure in insects and humans is associated with the ability of the OPs to bind to AChE and prevent the hydrolysis of acetylcholine (10). The present study demonstrated that the histopathological changes of the lungs in the 2-h, 5-day and 10-day HSMs groups were significantly less prominent compared to those in the control group. It was previously demonstrated that respiratory failure is a prominent characteristic of acute OP poisoning (11) and that the morbidity and mortality of acute OP poisoning is associated with respiratory failure (12). Therefore, it is hypothesized that the effectiveness of HSMs is at least partly associated with ameliorating MP-induced pulmonary edema.

The development of an effective and safe approach against OP toxicity may help to reduce the mortality associated with OP poisoning worldwide. Our results indicated that pretreatment with HSMs effectively and safely counteracts OP poisoning and may therefore be of benefit to individuals who are prone to exposure to OPs or nerve agents. In conclusion, the present study demonstrated a novel approach to effectively protecting against OPs toxicity and nerve agent-induced organ injury or death.

\section{Acknowledgements}

This study was supported by the Project of Fundamental Study Funds of the Shandong Provincial Education Department (grant no. J11LF56), the Doctoral Foundation of Yantai
University (grant no. YX12B30) and the Shandong Provincial Natural Science Foundation (grant no. ZR2010HQ049). The authors would like to thank Professor Lon Clark for the English language revision.

\section{References}

1. Soltaninejad K and Abdollahi M: Current opinion on the science of organophosphate pesticides and toxic stress: a systematic review. Med Sci Monit 15: RA75- RA90, 2009.

2. Bajgar J: Organophosphates/nerve agent poisoning: mechanism of action, diagnosis, prophylaxis, and treatment. Adv Clin Chem 38: 151-216, 2004.

3. Jia P, Wang Y, Yu M, et al: An organophosphorus hapten used in the preparation of monoclonal antibody and as an active immunization vaccine in the detoxication of soman poisoning. Toxicol Lett 187: 45-51, 2009.

4. Muggleton NG, Bowditch AP, Crofts HS, Scott EA and Pearce PC: Assessment of a combination of physostigmine and scopolamine as pretreatment against the behavioural effects of organophosphates in the common marmoset (Callithrix jacchus). Psychopharmacology (Berl) 166: 212-220, 2003.

5. Albuquerque EX, Pereira EF, Aracava Y, et al: Effective countermeasure against poisoning by organophosphorus insecticides and nerve agents. Proc Natl Acad Sci USA 103: 13220-13225, 2006.

6. Ashani Y, Peggins JO III and Doctor BP: Mechanism of inhibition of cholinesterases by huperzine A. Biochem Biophys Res Commun 184: 719-726, 1992.

7. Wang C, Zhang T, Ma H, Liu J, Fu F and Liu K: Prolonged effects of poly(lactic-co-glycolic acid) microsphere-containing huperzine $\mathrm{A}$ on mouse memory dysfunction induced by scopolamine. Basic Clin Pharmacol Toxicol 100: 190-195, 2007.

8. Choi SC: Interval estimation of the $\mathrm{LD}_{50}$ based on an up-and-down experiment. Biometrics 46: 485-492, 1990.

9. Aracava Y, Pereira EF, Akkerman M, Adler M and Albuquerque EX: Effectiveness of donepezil, rivastigmine, and (+/-)huperzine $\mathrm{A}$ in counteracting the acute toxicity of organophosphorus nerve agents: comparison with galantamine. J Pharmacol Exp Ther 331: 1014-1024, 2009.

10. Lu L, Wang X, Lang L and Fu F: Protective effect of reduced glutathione on the liver injury induced by acute omethoate poisoning. Environ Toxicol Pharmacol 30: 279-283, 2010

11. Munidasa UA, Gawarammana IB, Kularatne SA, Kumarasiri PV and Goonasekera CD: Survival pattern in patients with acute organophosphate poisoning receiving intensive care. J Toxicol Clin Toxicol 42: 343-347, 2004.

12. Tafuri J and Roberts J: Organophosphate poisoning. Ann Emerg Med 16: 193-202, 1987. 